\title{
PERCEPÇÃO AMBIENTAL DOS ALUNOS DE ENSINO MÉDIO DA ESCOLA ESTADUAL “EMÍLIO OSCAR HÜLLE” - MUNICÍPIO DE MARECHAL FLORIANO - ESPÍRITO SANTO
}

\author{
Rafaela Barreto Cazaroto ${ }^{1}$, Luciléia Gilles², Manuella Villar Amado ${ }^{3}$ * \\ Programa de Pós-graduação em Educação em Ciências e Matemática \\ Instituto Federal do Espírito Santo, Campus Vitória \\ Av. Vitória, 1729 -Prédio Administrativo, Programa Educimat, \\ Bairro Jucutuquara, Vitória, Espírito Santo. CEP 29040-780.
}

\begin{abstract}
RESUMO
A educação ambiental é um elemento estratégico na formação de ampla consciência crítica das relações sociais e de produção que situam a inserção humana na natureza. Para trabalhar a melhoria do meio ambiente é fundamental que ocorra mudanças de comportamento, de condutas e valores. Para isso, é preciso conhecer como o homem se relaciona com o meio e, é através da percepção, ou seja, dos sentidos, que ocorre a apreensão da realidade e consequentemente a sua interação como o meio ambiente. 0 rio Jucu possui uma extensão de cerca de $80 \mathrm{Km}$ até a sua foz, desaguando no Oceano Atlântico, sendo que o trecho do rio Jucu braço sul atravessa a cidade de Marechal Floriano e recebe grande quantidade de esgoto doméstico, apresentando-se assoreado e poluído. 0 objetivo desse trabalho foi investigar a percepção ambiental dos alunos do Ensino Médio sobre as diferentes concepções de meio ambiente, buscando sensibilizar os alunos sobre a importância do rio Jucu.
\end{abstract}

Palavras-chave: percepção ambiental; rio Jucu; educação ambiental.

\section{ABSTRACT}

Environmental education is a strategic element in the formation of broad critical awareness of the social relations and production that place the insertion in human nature. Evironmental education is a strategic element to create a broad critical awareness of the social relations and of production, that places human insertion in the nature. The environmental improvement task take on account some inner changes, such as in behaviour, values and actions. To reach this goal it's highly necessary to know how man relates to the evironmennnt and, it is through perception that occours the apprehension of reality and therefore man evironmental of reality and therefore man evironmental interaction. Jucu river has a length of about $80 \mathrm{~km}$ to its mouth, emptying into the Atlantic Ocean, and the section of river south arm Jucu through the town of Marechal Floriano and receives large amounts of domestic sewage, presenting silted and polluted. This study aims to investigate the environmental awareness of students EEEFM "Emilio Oscar Hülle" on the different conceptions of the environment, seeking to make the students aware the importance of the Jucu river. The research is embedded in the environmental education project "Recognizing the Jucu river: history, science and environmental issues".

Keywords: environmental awareness; Jucu river; environmental education.

\footnotetext{
${ }^{1}$ Aluna de IC da FAPES do Instituto Federal do Espírito Santo. Bacharel em Ciências Biológicas.

${ }^{2}$ Licenciada em Ciências Biológicas, M.Sc. - Docente da Rede Estadual de Educação Básica do Espírito Santo.

${ }^{3}$ Professora de Ciências Biológicas, D.Sc., Ifes - Campus Vila Velha - Docente do Programa de Pós-graduação em Educação em Ciências e Matemática do Instituto Federal do Espírito Santo. E-mail: manuellaamado@gmail.com
} 


\section{INTRODUÇÃOO}

A Educação ambiental é um elemento estratégico na formação de ampla consciência crítica das relações sociais e de produção que situam a inserção humana na natureza (LOUREIRO, 2000). Dessa forma a educação ambiental assume cada vez mais uma função transformadora, na qual a responsabilidade dos indivíduos com o meio ambiente é o objetivo principal para promover um novo tipo de desenvolvimento, o desenvolvimento sustentável (JACOBI, 2003).

A educação ambiental constitui uma área do conhecimento eminente e interdisciplinar, em razão dos diversos fatores interligados e necessários ao diagnostico e à intervenção que pressupõe. Historicamente, ela vem se impondo às preocupações de vários setores sociais como um campo conceitual, politico e ético (CASTRO \& BAETA, 2002). Para trabalhar a melhoria do meio ambiente é fundamental que ocorra mudanças de comportamento, de condutas e valores. Para isso, é preciso conhecer como o homem se relaciona com o meio e, é através da percepção, ou seja, dos sentidos, que ocorre a apreensão da realidade e consequentemente a sua interação como o meio ambiente (COELHO, 2002).

Percepção ambiental pode ser definida como sendo uma tomada de consciência do ambiente pelo homem, ou seja, o ato de perceber o ambiente que está inserido, aprendendo a proteger e cuidar do mesmo. 0 estudo da percepção ambiental é fundamental para que possamos compreender melhor as inter-relações entre o homem e o ambiente, suas expectativas, anseios satisfações e insatisfações (MACEDO et al. 2010).

A Declaração da ONU sobre o meio ambiente, afirma que "Os recursos naturais da Terra, incluindo o ar, a água, o solo, a flora e a fauna e, especificamente, parcelas representativas dos ecossistemas naturais, devem ser preservados em beneficio das gerações atuais e futuras, mediante um cuidado planejado ou administração adequada". Sabemos que o homem está constantemente agindo sobre o meio a fim de satisfazer as suas necessidades e desejos, cada indivíduo percebe, reage e responde diferentemente frente às ações sobre o meio (BEZERRA \& GONÇALVES, 2007). Para a formação de cidadãos que se preocupem e atuem de maneira significativa perante a natureza, é necessário que sejam desenvolvidos trabalhos que contribuam para a percepção do meio, este que o influencia e que é indispensável ao seu sustento, incluindo solo, clima, água, nutrientes e outros organismos (MARQUES et al., 2004). Através da percepção 
ambiental são estabelecidas as relações de afetividade do indivíduo para com o ambiente. A partir da formação de laços afetivos positivos, pode ocorrer a modificação dos valores ambientais atribuídos pelas pessoas (MACEDO, 2010).

Considerando que o estudo da percepção ambiental é de fundamental importância para que possamos compreender melhor as inter-relações entre o homem e o ambiente (FERNANDES et al. 2004), esse trabalho tem como objetivo analisar a percepção ambiental dos alunos de ensino médio da EEEFM “Emílio Oscar Hülle”, localizada no município de Marechal FlorianoES, verificando as diferentes concepções que os alunos tem sobre meio ambiente, dando ênfase aos recursos hídricos e em especial a bacia hidrográfica do Rio Jucu.

\section{PROCEDIMENTOS METODOLÓGICOS}

A Bacia Hidrográfica do Rio Jucu (Figura 1), localizada totalmente em território do estado do Espírito Santo é constituída de dois braços: Sul e Norte e sofre grandes impactos provenientes da ação antrópica (DEINA \& BOSCAGLIA, 2011). O Município de Marechal Floriano, banhado pelo braço sul do Rio Jucu, situa-se na região das montanhas, ficando a apenas $45 \mathrm{~km}$ da capital do Espírito Santo, Vitória. Seu território é de $284,84 \mathrm{~km}^{2}$ e a sua altitude média é de 544 metros. As coordenadas geográficas são: latitude 2024'48” e longitude 4040'26”. 0 relevo do município é montanhoso e acidentado. 0 clima é tropical de altitude, com temperatura amena durante a maior parte do ano. As áreas com matas remanescentes da Mata Atlântica localizam-se principalmente no alto dos morros. 0 restante da vegetação é formado por pastagens, plantio de café, culturas permanentes e temporárias (TERRA et al. 2009).

O trecho do Rio Jucu braço sul que atravessa a cidade de Marechal Floriano recebe esgoto e doméstico, apresentando-se assoreado e poluído (Figura 2). 0 estudo foi elaborado dentro do Projeto de Iniciação Científica Júnior "Reconhecendo o Rio Jucu: história, ciência e questões socioambiental", o projeto é financiado pela FAPES e desenvolvido na Escola Estadual de Ensino Fundamental e Médio Emílio Oscar Hülle em parceria com o Instituto Federal do Espírito Santo. São diretamente envolvidos 10 alunos do ensino médio e um de graduação, além de professores da EEEFM Emílio Oscar Hülle e pesquisadores do IFES, visando: resgatar a historia da ocupação do entorno do Rio Jucu, descrever as condições físico-químicas da água e as percepções da comunidade escolar e do entorno do rio sobre o mesmo. 


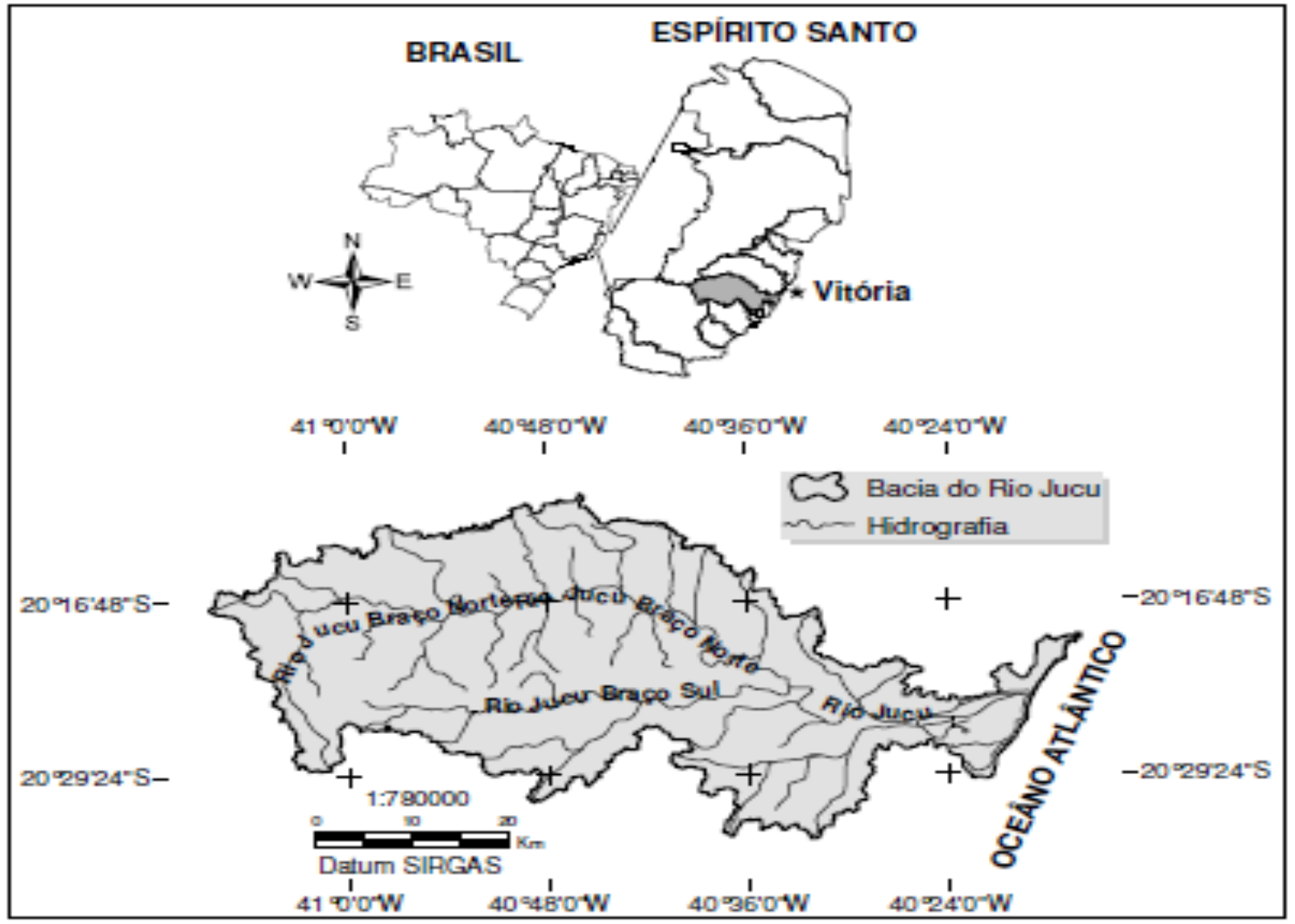

FIGURA 1 - Localização Geográfica da Bacia Hidrográfica do Rio Jucu. Fonte: ALMEIDA, 2007.

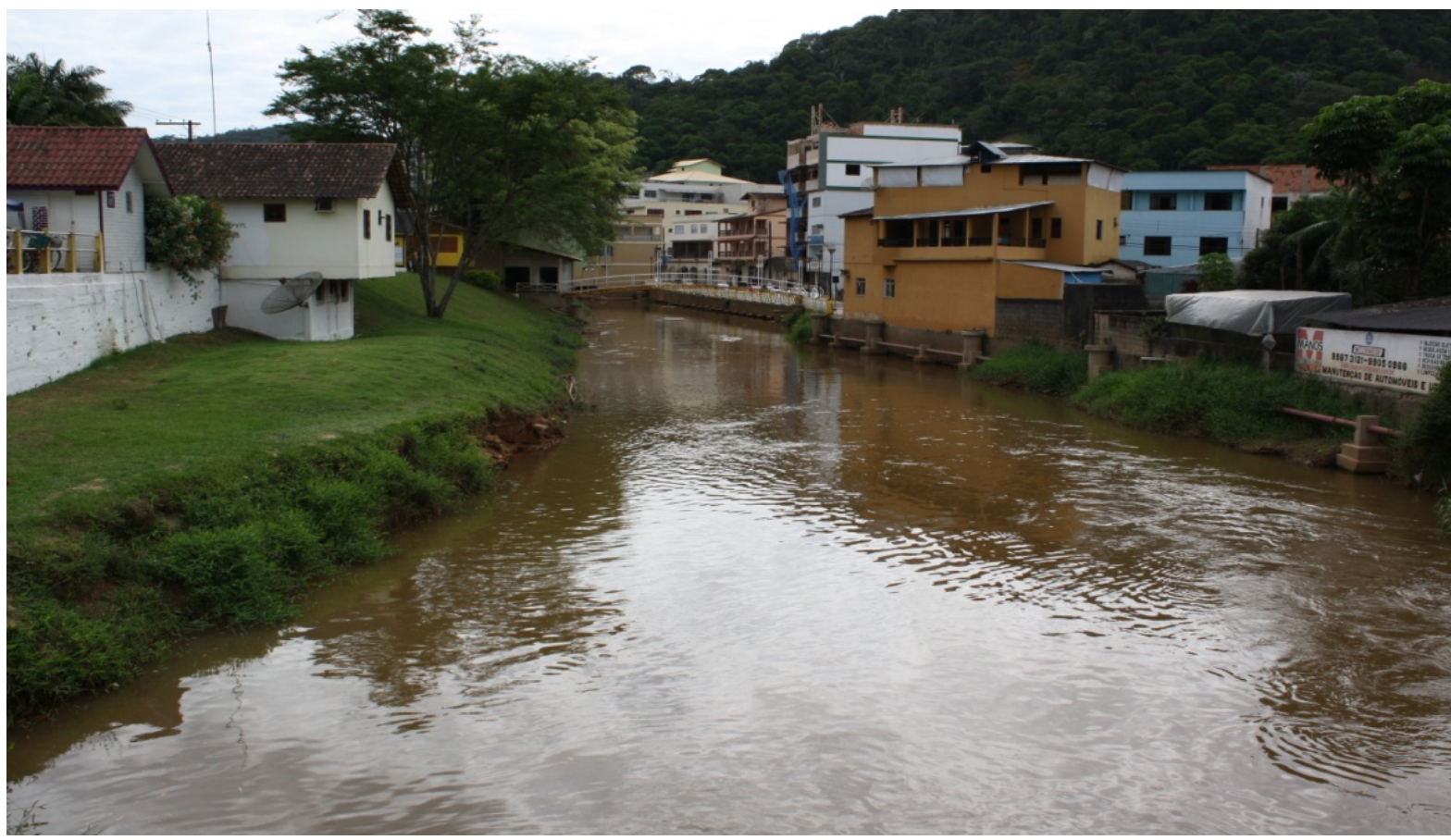

FIGURA 2 - Rio Jucu braço Sul no centro de Marechal Floriano. Foto: Luciléia Gilles. 
Com o intuito de verificar a concepção de meio ambiente dos alunos de ensino médio da EEEFM Emílio Oscar Hülle, foi aplicado um questionário em um total de 87 alunos, de diferentes idades (Figura 3), matriculados no $1^{\circ}$ ano, $2^{\circ}$ ano e $3^{\circ}$ ano do ensino médio. Para obtenção dos dados os alunos responderam a seguinte pergunta: 0 que você entende como meio ambiente? .

Considerando a variedade de resposta dos alunos, as concepções de meio ambiente foram categorizadas segundo Pereira (2010), em cinco categorias: Generalizante, naturalista, biocêntrica, antropocêntrica e multidimensional.

\section{RESULTADOS E DISCUSSÃO}

Os alunos de ensino médio que responderam o questionário, a maioria possuía 16 anos de idade, sendo que a faixa etária variou entre 14 e 18 anos (Figura 3). Os sujeitos residiam tanto no centro como em vilarejos no interior de Marechal Floriano.

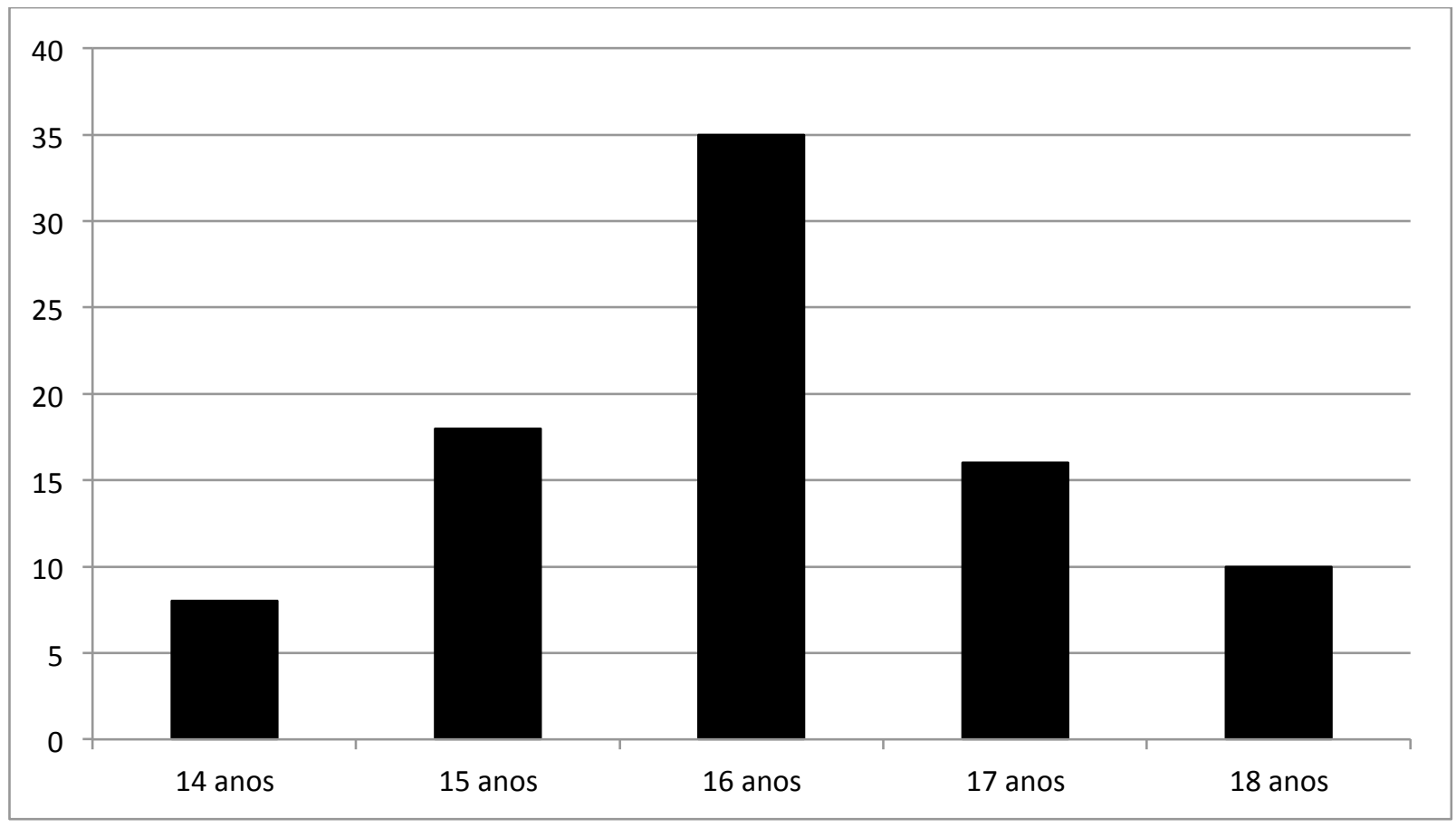

FIGURA 3 - Faixa etária dos alunos que participaram do questionário. 
Os resultados das análises dos questionários sobre as concepções dos alunos quanto ao meio ambiente (Tabela 1), revelaram que a maioria dos alunos tem uma concepção naturalista, $(32,2 \%)$ tratando o meio ambiente como sinônimo de natureza e como o lugar onde os seres vivos habitam, enfatizando os fatores bióticos e abióticos na composição do meio ou generalizante $(24,1 \%)$, definindo meio ambiente de forma ampla, vaga e abstrata.

Outra concepção bastante presente na percepção de meio ambiente é a biocêntrica $(20,7 \%)$, onde, no repertório conceitual, considera-se o ser humano como mais um ser vivo que se encontra inserido no meio ambiente, sem que este, necessariamente, tenha utilidade para o homem. A concepção antropocêntrica, que se caracteriza quando o meio ambiente é considerado a serviço do homem e de sua existência, também aparece, mas em porcentagens menores $(13,8 \%)$.

A concepção Multidimensional, que considera o meio ambiente como um sistema complexo, resultante da interação entre fatores diversos como biológicos, físicos, químicos, culturais, históricos, políticos, econômicos, numa configuração em constante mudança, não ocorreu em nenhum dos relatos e $(9,2 \%)$ não souberam ou não responderam o conceito de meio ambiente.

Considerando que o termo meio ambiente é usado para definir a relação entre os conjuntos sociais e naturais que sustentam a existência da vida no planeta, observamos que para a maior parte dos alunos da EEEFM Emilio Oscar Hulle o homem não está inserido no meio ambiente, de forma que a visão está mais focada em uma concepção naturalista e generalizante. Esses resultados apontam para a necessidade de projetos de educação ambiental que visem à modificação da percepção ambiental focada na importância do rio Jucu valorizando as questões socioambientais e garantido uma mudança de postura com vistas à restauração e conservação do rio Jucu. 
TABELA 1- Concepções de meio ambiente dos alunos da EEEFM Emílio Oscar Hulle, Marechal Floriano, Espírito Santo.

\begin{tabular}{|c|c|c|}
\hline Conceitos & Depoimentos & $\begin{array}{c}\text { Alunos } \\
\text { (Quantidade) }\end{array}$ \\
\hline Antropocêntrica & $\begin{array}{l}\text { "Principal fonte de vida para os seres humanos". } \\
\text { "O meio ambiente é muito importante para o homem". } \\
\text { "Que deve ser preservado devido o fato dos seres humanos serem } \\
\text { prejudicados futuramente". } \\
\text { "É muito importante se nós não cuidarmos nosso meio ambiente será } \\
\text { totalmente destruído". }\end{array}$ & 12 \\
\hline Biocêntrica & $\begin{array}{l}\text { "É um local onde os seres vivos dependem dele e até nos mesmos, pois o } \\
\text { meio ambiente nos trás uma vida mais pura e saudável". } \\
\text { "É um meio ligado entre plantas, animais, cachoeiras e rios e também o ser } \\
\text { humano, um ajuda na sobrevivência do outro, um precisa do outro, seja } \\
\text { para existência, alimentação, etc." } \\
\text { "É um meio em que vivemos, o ambiente, o lugar, o que está a nossa volta. } \\
\text { "Entendo que é as matas, os rios, resumindo a natureza, que nós habitantes } \\
\text { estamos destruindo". } \\
\text { "Meio ambiente é o local onde todos nós vivemos, ou não. Sem ele não } \\
\text { existiria gente. Ele é o local onde vivem todos os animais, onde vive as } \\
\text { árvores, onde nascem as águas, para nós bebermos. Por isso temos que } \\
\text { preserva-lo". }\end{array}$ & 18 \\
\hline Generalizante & $\begin{array}{l}\text { "É o meio onde vivemos". } \\
\text { "É o lugar onde vivemos". } \\
\text { "Um lugar deve estar sempre limpo". } \\
\text { "É onde os seres vivos se desenvolvem". } \\
\text { "Meio ambiente é um lugar limpo e bem cuidado". }\end{array}$ & 21 \\
\hline Multidimensional & & $\mathbf{0}$ \\
\hline Naturalista & $\begin{array}{l}\text { "Rios, florestas, animais, tudo isso para mim é meio ambiente". } \\
\text { "Todos os animais e plantas e temos que preserva-los". } \\
\text { "Fauna e flora, plantas, animais, um ambiente onde tem seres vivos". } \\
\text { "É o que faz parte da natureza". } \\
\text { "O espaço em que vivemos que é natural e nasce, cresce e reproduz sem } \\
\text { interferência humana". }\end{array}$ & 28 \\
\hline Nulo & & 8 \\
\hline TOTAL & & 87 \\
\hline
\end{tabular}

\section{CONSIDERAÇÕES FINAIS}

As pesquisas de percepção ambiental são de extrema importância para se promover maior conscientização ambiental. 0 estudo da percepção ambiental dos alunos de Marechal Floriano, demonstrou que podemos atribuir valores e importâncias diferenciadas para o meio ambiente. Os diferentes conceitos de meio ambiente, se aplicados exclusivamente aos seus aspectos naturais, não permitem apreciar interdependência nem a contribuição das ciências à compreensão e melhoria do ambiente. O predomínio das concepções generalizante e naturalista, evidenciou, a necessidade de haver projetos de educação ambiental implementados nas escolas, como o projeto "Reconhecendo o rio Jucu: história, ciências e questões socioambientais". 


\section{AGRADECIMENTOS}

Os autores agradecem à Fundação de Amparo à Pesquisa do Espírito Santo (FAPES), ao Instituto Federal do Espírito Santo (IFES) e à EEEFM Emílio Oscar Hülle, aos alunos que responderam os questionários e a Secretaria de Estado da Educação do Espírito Santo pela oportunidade e apoio à realização desse projeto de pesquisa.

\section{REFERÊNCIAS}

BEZERRA, T. M. O.; GONÇALVES, A. A. C. Concepções de meio ambiente e educação ambiental por professores da Escola Agrotécnica Federal de Vitória de Santo Antão-PE. Biotemas. v. 20, n. 3, p. 115-125, 2007.

CASTRO, R. S.; BAETA, A. M. Autonomia intelectual: condição necessária para o exercício da cidadania. Educação ambiental: repensando o espaço da cidadania. $2^{\underline{a}}$ edição. Editora cortez. 2002. p. 99- 107.

ESTOCOLMO, 1972. Declaração da ONU sobre o Meio Ambiente Humano. Disponível em:<http://www.apoema.com.br/Declaracao_ONU_Meio_AH_Estocolmo1972\%20.pdf>. Acesso em 13 de junho de 2012.

DEINA, Miquelina Aparecida; BOSCAGLIA, Fabiano. O uso e ocupação do solo no baixo curso do Rio Jucu em Vila Velha sob a ótica de seu plano diretor municipal. 2011; 19p. Disponível em: < http://xiisimpurb2011.com.br/app/web/arq/trabalhos/4e311d38b9c3bde949f64 a58d4ad9b17.pdf>. Acesso em 13 de junho de 2012.

FERNANDES, R. S; SOUZA, V. J; PELISSARI, V. B; FERNANDES, S. T. Uso da percepção ambiental como instrumento de gestão em aplicações ligadas às áreas educacional, social e ambiental. Disponível em: <http://www.redeceas.esalq.usp.br/noticias/Percepcao_Ambiental.pdf>. Acesso em 22 de novembro, 2012.

JACOBI, P. Educação ambiental, cidadania e sustentabilidade. Caderno de pesquisa, n¹18, 2003. p. 189-205.

LOUREIRO, C.F.B. 0 movimento de cidadania pelas águas do Rio Paraíba do Sul, Relatório de Pesquisa, Instituto de pesquisa Databrasil? Ministerio do meio ambiente, 1997.

MACEDO, R. L.G.; MACEDO, S. B.; VENTURIN, N.; ANDRETTA, V. ; AZEVEDO, F. C. S. Pesquisas de percepção ambiental para o entendimento e direcionamento da conduta ecoturística em unidades de conservação. Universidade Federal de Lavras - Departamento de Ciências Florestais. Disponível em: <http://www.physis.org.br/ecouc/Artigos/Artigo50.pdf>. Acesso em: 12/07/2012. 
MARQUES, L. M; CARNIELLO, M. A; NETO, G. G. A percepção ambiental como papel fundamental na realização de pesquisa em educação ambiental. Travessias, ed. 10. 2004. P. 337-349.

PEREIRA, M. G. Pelas ondas do saber: Conhecer, agir e transformar o ambiente. Ciências : ensino fundamental / Coordenação Antônio Carlos Pavão. Brasília : Ministério da Educação, Secretaria de Educação Básica. v.18, 212 p. 2010.

TERRA, V. R; PRATTES'SANTOS, R; ALIPRANDI, R. B; BARCELOS, M; AS MARBACH, P; LD MARTINS, J; JR AZEVEDO, R. R; BARBIÉRI, R. Monitoramento do Rio Jucu Braço Sul: caracterização e avaliação dos parâmetros físico-químicos e microbiológicos. Natureza Online v.7, n. 1, p. 5-11, 2009. 